\title{
2-Imidazole as a Substitute for the Electrophilic Group Gives Highly Potent Prolyl Oligopeptidase Inhibitors
}

\section{Pätsi, Henri T.}

2021-10-14

Pätsi , H T , Kilpeläinen , T P , Auno , S , Dillemuth , P M J , Arja , K, Lahtela-Kakkonen , M K, Myöhänen , T T \& Wallen , E A A 2021 , ' 2-Imidazole as a Substitute for the Electrophilic Group Gives Highly Potent Prolyl Oligopeptidase Inhibitors ' , ACS Medicinal Chemistry Letters , vol. 12 , no. 10 , pp. 1578-1584 . https://doi.org/10.1021/acsmedchemlett.1c00399

http://hdl.handle.net/10138/336056

https://doi.org/10.1021/acsmedchemlett.1c00399

cc_by

publishedVersion

Downloaded from Helda, University of Helsinki institutional repository.

This is an electronic reprint of the original article.

This reprint may differ from the original in pagination and typographic detail.

Please cite the original version. 


\title{
2-Imidazole as a Substitute for the Electrophilic Group Gives Highly Potent Prolyl Oligopeptidase Inhibitors
}

\author{
Henri T. Pätsi, * Tommi P. Kilpeläinen, Samuli Auno, Pyry M. J. Dillemuth, Khaled Arja, \\ Maija K. Lahtela-Kakkonen, Timo T. Myöhänen, and Erik A. A. Wallén
}

Cite This: ACS Med. Chem. Lett. 2021, 12, 1578-1584

Read Online

ACCESS | 亗 Metrics \& More | 回 Article Recommendations | Su Supporting Information

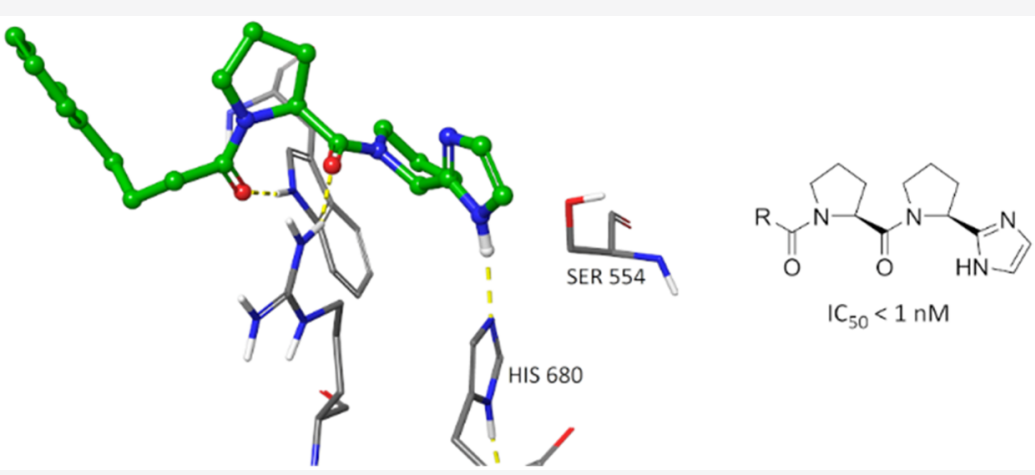

ABSTRACT: Different five-membered nitrogen-containing heteroaromatics in the position of the typical electrophilic group in prolyl oligopeptidase (PREP) inhibitors were investigated and compared to tetrazole. The 2-imidazoles were highly potent inhibitors of the proteolytic activity. The binding mode for the basic imidazole was studied by molecular docking as it was expected to differ from the acidic tetrazole. A new putative noncovalent binding mode with an interaction to His680 was found for the 2-imidazoles. Inhibition of the proteolytic activity did not correlate with the modulating effect on protein-protein-interaction-derived functions of PREP (i.e., dimerization of alpha-synuclein and autophagy). Among the highly potent PREP inhibiting 2-imidazoles, only one was also a potent modulator of PREP-catalyzed alpha-synuclein dimerization, indicating that the linker length on the opposite side of the molecule from the five-membered heteroaromatic is critical for the disconnected structure-activity relationships.

KEYWORDS: Prolyl oligopeptidase, triazole, imidazole, pyrazole, alpha-synuclein, autophagy

$\mathrm{P}$ rolyl oligopeptidase (PREP EC 3.4.21.26, also abbreviated $\mathrm{POP})$ is a serine protease with endopeptidase activity, cleaving proline-containing peptides up to 30 amino acids long. ${ }^{1,2}$ Initially, it was suggested that PREP could regulate the degradation of proline containing neuropeptides such as substance $\mathrm{P}$, arginine, vasopressin, and thyrothropin-releasing hormone (for a review, see Garcia-Horsman et al. ${ }^{3}$ ). However, as PREP is mainly a cytosolic enzyme, ${ }^{4}$ its physiological role is more likely related to regulating the function of other proteins rather than cleaving neuropeptides. To support this, the effects of PREP inhibitors on neuropeptide levels have been inconclusive. ${ }^{5,6}$ However, inhibition of the proteolytic activity should not be overlooked as it is the mechanism of action in other therapeutic areas. Bayer has recently patented inhibitors targeting peripheral PREP for the treatment of chronic obstructive pulmonary disease ${ }^{7,8}$ and has a PREP inhibitor in their development pipeline. ${ }^{9}$

We have recently shown that PREP can regulate alphasynuclein $(\alpha \mathrm{Syn})$ and protein phosphatase $2 \mathrm{~A}(\mathrm{PP} 2 \mathrm{~A})$ via direct protein-protein interactions (PPIs), leading to increased $\alpha$ Syn aggregation ${ }^{10}$ and decreased autophagy, ${ }^{11,12}$ respectively. Small-molecular PREP inhibitors have been shown to reduce $\alpha$ Syn aggregation and increase the clearance of $\alpha$ Syn aggregates via enhanced autophagy in several in vitro and in vivo models. ${ }^{11,13-15}$ Thus, modulation of PREP with small-molecular ligands might be a potential therapeutic strategy to tackle several routes leading to neurodegenerative diseases related to abnormal protein processing such as Parkinson's disease and Alzheimer's disease. We have also demonstrated that the effects of PREP ligands on $\alpha$ Syn dimerization and autophagy have no direct correlation to their IC $_{50}$ values. ${ }^{15,16}$ Inhibition of the proteolytic activity has been thoroughly studied, but we are still learning how proteinprotein interactions of PREP are regulated. PREP is a highly

Received: July 21, 2021

Published: September 17, 2021 
Scheme 1. Synthesis of Heteroaryls ${ }^{a}$

a: Xaa $=$ Pro
b: Xaa $=$ Ala

c: Xaa $=$ Sar

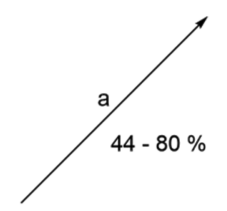

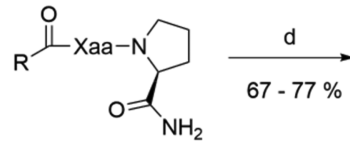

3a-c: $\mathrm{R}=\mathrm{Ph}\left(\mathrm{CH}_{2}\right)_{2}$

4a, 4b: $\mathrm{R}=\mathrm{Ph}\left(\mathrm{CH}_{2}\right)_{3}$

5a, 5b: $\mathrm{R}=\mathrm{Ph}\left(\mathrm{CH}_{2}\right)_{4}$

6a, 6b: $\mathrm{R}=$ Thien-2-yl- $\left(\mathrm{CH}_{2}\right)_{3}$

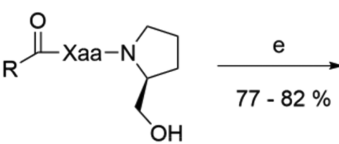

7a: $\mathrm{R}=\mathrm{Ph}\left(\mathrm{CH}_{2}\right)_{2}$

8a, 8b: $\mathrm{R}=\mathrm{Ph}\left(\mathrm{CH}_{2}\right)_{3}$

9a: $\mathrm{R}=\mathrm{Ph}\left(\mathrm{CH}_{2}\right)_{4}$

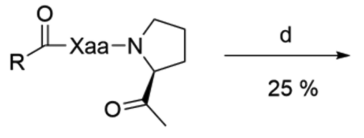

10a: $\mathrm{R}=\mathrm{Ph}\left(\mathrm{CH}_{2}\right)_{3}$<smiles>[R]C(=O)[Y10]N1CCC[C@H]1C#N</smiles>

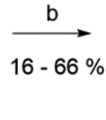

11a-c: $\mathrm{R}=\mathrm{Ph}\left(\mathrm{CH}_{2}\right)_{2}$

12a, 12b: $\mathrm{R}=\mathrm{Ph}\left(\mathrm{CH}_{2}\right)_{3}$

13a, 13b: $\mathrm{R}=\mathrm{Ph}\left(\mathrm{CH}_{2}\right)_{4}$

14a, 14b: $\mathrm{R}=$ Thien-2-yl- $\left(\mathrm{CH}_{2}\right)_{3}$<smiles>[R]C(=O)[Y19]N1CCCC1c1nnc[nH]1</smiles>

20a, 20b: $\mathrm{R}=\mathrm{Ph}\left(\mathrm{CH}_{2}\right)_{3}$

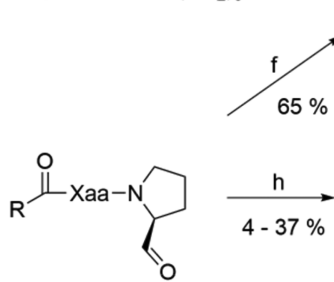

21a: $\mathrm{R}=\mathrm{Ph}\left(\mathrm{CH}_{2}\right)_{2}$

22a, 22b: $\mathrm{R}=\mathrm{Ph}\left(\mathrm{CH}_{2}\right)$

23a: $\mathrm{R}=\mathrm{Ph}\left(\mathrm{CH}_{2}\right)_{4}$

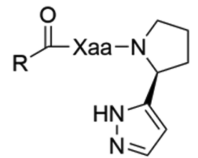

30a: $\mathrm{R}=\mathrm{Ph}\left(\mathrm{CH}_{2}\right)_{3}$<smiles>[R]C(=O)[R14]N1CCCC1c1nnn[nH]1</smiles>

15a-c: $\mathrm{R}=\mathrm{Ph}\left(\mathrm{CH}_{2}\right)_{2}$ 1a, 1b: $\mathrm{R}=\mathrm{Ph}\left(\mathrm{CH}_{2}\right)_{3}$ 16a, 16b: $\mathrm{R}=\mathrm{Ph}\left(\mathrm{CH}_{2}\right)_{4}$ 17a, 17b: $\mathrm{R}=$ Thien-2-yl- $\left(\mathrm{CH}_{2}\right)_{3}$
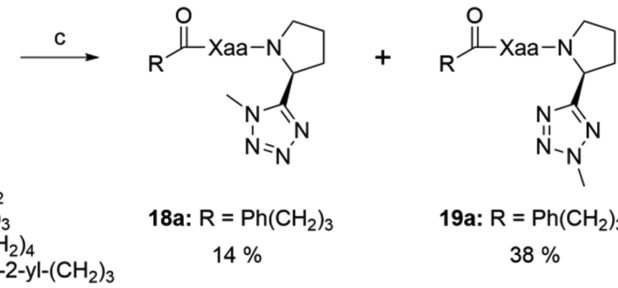

18a: $\mathrm{R}=\mathrm{Ph}\left(\mathrm{CH}_{2}\right)_{3}$

$14 \%$

19a: $\mathrm{R}=\mathrm{Ph}\left(\mathrm{CH}_{2}\right)_{3}$

$38 \%$

${ }^{a}$ Reagents and conditions: (a) TFAA, Et ${ }_{3} \mathrm{~N} / \mathrm{THF}, 0{ }^{\circ} \mathrm{C}$; (b) $\mathrm{NH}_{4} \mathrm{Cl}, \mathrm{NaN}_{3} / \mathrm{DMF}, 100{ }^{\circ} \mathrm{C}$; (c) $\mathrm{MeI}_{2} \mathrm{~K}_{2} \mathrm{CO}_{3} / \mathrm{DMF}$; (d) (1) DMF-DMA/reflux (2) $\mathrm{N}_{2} \mathrm{H}_{4} \cdot \mathrm{H}_{2} \mathrm{O} / \mathrm{AcOH}, 90{ }^{\circ} \mathrm{C}$; (e) TEMPO, NaOCl, NaBr, NaHCO $3 / \mathrm{DCM}, 0{ }^{\circ} \mathrm{C}$; (f) Dimethyl 2-oxopropylphosphonate, p-ABSA, $\mathrm{K}_{2} \mathrm{CO}_{3} / \mathrm{MeCN}$ $\mathrm{MeOH}$; (g) TMSN 3 , CuI/DMF, $100{ }^{\circ} \mathrm{C}$; (h) $\mathrm{NH}_{3}$, Glyoxal/MeOH; (i) (1) TosMIC, NaCN/EtOH (2) $\mathrm{NH}_{3}$, reflux.

dynamic protein, where inhibitor binding restricts its conformational freedom, ${ }^{17}$ and our working hypothesis is that the functions of PREP are dependent on what conformations PREP can adopt. The affinity of small molecules to binding sites outside the area comprised by the substrate binding pockets $S 1, S 2$, and S3 could result in different outcomes in the regulation of the conformational freedom of PREP and thereby in different regulation of its functions.

In our previous study, we showed that a tetrazole ring could be directly attached to the inhibitor structure at the position of the electrophilic group without the important carbonyl group, resulting in moderately potent inhibitors $\mathbf{1 a}-\mathbf{e}$, and that the tetrazole ring was not a bioisostere of a carboxylic acid group. ${ }^{16}$ In addition, the tetrazoles demonstrated clearly disconnected structure-activity relationships (SARs) for inhibition of the proteolytic activity and modulation of $\alpha$ Syn dimerization. In the present study, other nitrogen-containing five-membered heteroaromatics with different hydrogen-bonding capabilities and charges at physiological $\mathrm{pH}$ were investigated. Some additional tetrazoles were also synthesized to complete the series. These compounds were also compared to a closely resembling PREP inhibitor 2a, where both an electrophilic carbonyl group as well as a five-membered heteroaromatic are present. $^{18}$
We demonstrate here that the 2-imidazole ring is highly superior for inhibition of the proteolytic activity of PREP compared with the other heteroaromatics. Additionally, molecular docking at the active site for the most potent inhibitors revealed a new putative noncovalent binding mode. The new compound series presented in this study also gives specific information on the disconnected SARs. Inhibition of the proteolytic activity, modulation of $\alpha$ Syn dimerization, and modulation of autophagy are presented for all compounds, including novel autophagy results for the previously reported tetrazoles.

The starting compounds $\mathbf{3 - 1 0}$ were synthesized analogously to the previously reported procedure. ${ }^{16}$ These were then used to synthesize the different heteroaryls according to Scheme 1. The tetrazoles 15-17 were synthesized from 3-6 according to the previously reported procedure. ${ }^{16}$ Compound 1 a was reacted with MeI to obtain the methylated tetrazoles 18a and 19a. We first made an attempt to synthesize compound 20a by coupling 1,2,4-triazolylpyrrolidine to $N$-(4-phenylbutanoyl)-L-proline. However, as this was unsuccessful, the 1,2,4-triazoles 20a and 20b were instead synthesized from the corresponding prolinamides $\mathbf{4 a}$ and $\mathbf{4 b}$. They were first reacted with DMF-DMA to receive an intermediate, which was then immediately reacted with $\mathrm{N}_{2} \mathrm{H}_{4} \cdot{ }^{19}$ Compound 10a was converted to compound 30a using the same method. The 
Table 1. Activities of the Synthesized Compounds<smiles>[R]C(=O)[Y19]N1CCC[C@H]1[AlH2]</smiles>

\begin{tabular}{|c|c|c|c|c|c|c|}
\hline compound & Хаa & $\mathrm{Ar}$ & $\mathrm{R}$ & $\mathrm{IC}_{50}(\mathrm{nM})(95 \% \mathrm{CI})$ & $\begin{array}{l}\alpha \text {-synuclein dimerization at } \\
10 \mu \mathrm{M}(\%)^{a}\end{array}$ & $\underset{(\%)^{b}}{\text { autophagy at }} 10 \mu \mathrm{M}$ \\
\hline KYP-2047 & L-Pro & nitrile & $\mathrm{Ph}\left(\mathrm{CH}_{2}\right)_{3^{-}}$ & $0.2(0.17-0.29)^{c}$ & $75^{d}(1.9)$ & $89^{d}(3.4)$ \\
\hline $1 \mathrm{a}$ & L-Pro & tetrazolyl & $\mathrm{Ph}\left(\mathrm{CH}_{2}\right)_{3^{-}}$ & $12(9.9-15)^{e}$ & $82^{e}(6.8)$ & $92(2.3)$ \\
\hline $1 b$ & L-Ala & tetrazolyl & $\mathrm{Ph}\left(\mathrm{CH}_{2}\right)_{3^{-}}$ & $130(71-230)^{e}$ & $75^{e}(4.9)$ & $71(6.2)$ \\
\hline 1c & Sar & tetrazolyl & $\mathrm{Ph}\left(\mathrm{CH}_{2}\right)_{3^{-}}$ & $11000(8100-14000)^{e}$ & $75^{e}(7.7)$ & $84(3.4)$ \\
\hline $1 d$ & L-MeAla & tetrazolyl & $\mathrm{Ph}\left(\mathrm{CH}_{2}\right)_{3^{-}}$ & $27000(22000-33000)^{e}$ & $75^{e}(7.3)$ & $93(4.4)$ \\
\hline $1 e$ & Gly & tetrazolyl & $\mathrm{Ph}\left(\mathrm{CH}_{2}\right)_{3^{-}}$ & $210000^{e, f}$ & $77^{e}(6.2)$ & $90(6.2)$ \\
\hline $2 a^{g}$ & L-Pro & imidazole-2-carbonyl & $\mathrm{Ph}\left(\mathrm{CH}_{2}\right)_{3^{-}}$ & $<1(43 \%)^{h}$ & $99(7.6)$ & $95(1.0)$ \\
\hline $15 a$ & L-Pro & tetrazolyl & $\mathrm{Ph}\left(\mathrm{CH}_{2}\right)_{2^{-}}$ & $1000(790-1300)$ & $116(3.1)$ & $96(4.7)$ \\
\hline $15 b$ & L-Ala & tetrazolyl & $\mathrm{Ph}\left(\mathrm{CH}_{2}\right)_{2^{-}}$ & $3900(3100-4800)$ & $98(2.4)$ & $90(4.7)$ \\
\hline $15 \mathrm{c}$ & Sar & tetrazolyl & $\mathrm{Ph}\left(\mathrm{CH}_{2}\right)_{2^{-}}$ & $62000(35000-110000)$ & $95(10)$ & $95(2.7)$ \\
\hline $16 a$ & L-Pro & tetrazolyl & $\mathrm{Ph}\left(\mathrm{CH}_{2}\right)_{4^{-}}$ & $770(540-1000)$ & $102(4.6)$ & $98(5.4)$ \\
\hline $16 b$ & L-Ala & tetrazolyl & $\mathrm{Ph}\left(\mathrm{CH}_{2}\right)_{4^{-}}$ & $5000(4000-6100)$ & $92(4.7)$ & $94(5.7)$ \\
\hline $17 \mathbf{a}$ & L-Pro & tetrazolyl & thien-2-yl $\left(\mathrm{CH}_{2}\right)_{3}$ - & $94(57-150)$ & $87(9.3)$ & $87(5.1)$ \\
\hline $17 \mathrm{~b}$ & L-Ala & tetrazolyl & thien-2-yl $\left(\mathrm{CH}_{2}\right)_{3}$ - & $1100(920-1500)$ & $93(5.9)$ & $92(5.0)$ \\
\hline $18 \mathbf{a}$ & L-Pro & 1-methyltetrazolyl & $\mathrm{Ph}\left(\mathrm{CH}_{2}\right)_{3^{-}}$ & $520000^{f}$ & $105(2.2)$ & $88(1.5)$ \\
\hline $19 a$ & L-Pro & 2-methyltetrazolyl & $\mathrm{Ph}\left(\mathrm{CH}_{2}\right)_{3^{-}}^{-}$ & $12000(7800-17000)$ & $101(5.4)$ & $85(2.9)$ \\
\hline 20a & L-Pro & 1,2,4-triazolyl & $\mathrm{Ph}\left(\mathrm{CH}_{2}\right)_{3^{-}}$ & $29000(21000-40000)$ & $96(4.1)$ & $87(4.0)$ \\
\hline $20 \mathrm{~b}$ & L-Ala & 1,2,4-triazolyl & $\mathrm{Ph}\left(\mathrm{CH}_{2}\right)_{3^{-}}^{-}$ & $55000(30000-100000)$ & $110(3.7)$ & $91(5.5)$ \\
\hline $25 a$ & L-Pro & 1,2,3-triazolyl & $\mathrm{Ph}\left(\mathrm{CH}_{2}\right)_{3}$ & $1100(870-1500)$ & $104(5.1)$ & $93(5.2)$ \\
\hline $26 a$ & L-Pro & imidazol-2-yl & $\mathrm{Ph}\left(\mathrm{CH}_{2}\right)_{2^{-}}$ & $<1(41 \%)^{h}$ & $89(6.3)$ & $102(4.3)$ \\
\hline $27 a$ & L-Pro & imidazol-2-yl & $\mathrm{Ph}\left(\mathrm{CH}_{2}\right)_{3-}^{-}$ & $<1(25 \%)^{h}$ & $72(3.3)$ & $96(7.3)$ \\
\hline $27 \mathrm{~b}$ & L-Ala & imidazol-2-yl & $\mathrm{Ph}\left(\mathrm{CH}_{2}\right)_{3^{-}}$ & $2100(1700-2600)$ & $110(2.7)$ & $106(5.3)$ \\
\hline $28 \mathrm{a}$ & L-Pro & imidazol-2-yl & $\mathrm{Ph}\left(\mathrm{CH}_{2}\right)_{4^{-}}$ & $<1(20 \%)^{h}$ & $110(2.0)$ & $102(4.3)$ \\
\hline $29 a$ & L-Pro & imidazol-4-yl & $\mathrm{Ph}\left(\mathrm{CH}_{2}\right)_{3-}^{-}$ & $44(19-100)$ & $98(7.1)$ & $92(1.1)$ \\
\hline $30 a$ & L-Pro & pyrazol-3-yl & $\mathrm{Ph}\left(\mathrm{CH}_{2}\right)_{3^{-}}$ & $70000(52000-94000)$ & $99(7.1)$ & $89(4.0)$ \\
\hline
\end{tabular}

${ }^{a}$ Luminescence signal percentage of DMSO control with SEM. ${ }^{b}$ GFP signal percentage of DMSO control with SEM. ${ }^{c}$ Jarho et al. ${ }^{26}$ measured with porcine brain homogenate. ${ }^{d}$ Kilpeläinen et al. ${ }^{15}{ }^{e}$ Kilpeläinen et al. ${ }^{16}{ }^{f}$ Confidence interval could not be determined as $\mathrm{IC}_{50}$ value is higher than the maximum concentration used. ${ }^{g}$ First reported by Tsutsumi et al. ${ }^{18}{ }^{h}$ PREP activity at $1 \mathrm{nM}$ inhibitor concentration compared to control.

alcohols 7-9 were oxidized to the corresponding aldehydes 21-23 using TEMPO and $\mathrm{NaOCl}$ with excellent yields. ${ }^{20}$ The 2-imidazoles 26-28 were then synthesized from the aldehydes using ammonia and glyoxal. ${ }^{21}$ The 4-imidazole $29 \mathrm{a}$ was synthesized from the aldehyde 22 a using a TosMIC reaction. ${ }^{22}$ To synthesize compound $\mathbf{2 5 a}$, the Ohira-Bestmann reagent was first generated from dimethyl 2-oxopropylphosphonate using $p$-ABSA, which was then used to convert the aldehyde to alkyne 24a. ${ }^{23}$ The alkyne was then reacted with $\mathrm{TMSN}_{3}$ catalyzed by $\mathrm{CuI}$ to acquire the 1,2,3-triazole $25 \mathrm{a}^{24}$

Inhibition of the proteolytic activity $\left(\mathrm{IC}_{50}\right)$ of PREP was determined using purified recombinant porcine $\mathrm{PREP}^{25}$ as previously described. ${ }^{16}$ The results are shown in Table 1 .

Compounds $\mathbf{1 a}$ and $\mathbf{1 b}$ were the two most potent tetrazoles in the previous study. ${ }^{16}$ Both prolonging and shortening the linker in them by one carbon atom, resulting in compounds 15a, 15b, 16a, and 16b, reduced the inhibitory activity. Replacement of the phenyl group by a 2-thienyl group, resulting in compounds $17 \mathbf{a}$ and $17 \mathbf{b}$, also reduced the inhibitory activity. In all these cases the inhibitory activities were reduced by a factor in the range of 10 to 80 . Furthermore, the 1- and 2-methylated tetrazoles $18 \mathrm{a}$ and 19a, respectively, had significantly lower inhibitory activities compared with the corresponding tetrazole 1a. The two methylated tetrazoles contained about $15 \%$ of the other regioisomer (according to UPLC-MS) as they could not be fully separated from each other. As the 1-methylated tetrazole $\mathbf{1 8 a}$ is less active, its measured activity could be mostly derived from the 2methylated tetrazole 19a that it contains, and the 2-methylated tetrazole 19a may have a slightly lower $\mathrm{IC}_{50}$ value than indicated here.

The role of the negative charge, which is present in tetrazolecontaining ligands at physiological $\mathrm{pH}$, in the binding of the inhibitor was investigated by replacing the tetrazole ring of 1a and $\mathbf{2 a}$ with different triazoles. The 1,2,3-triazole 25a was more potent than the 1,2,4-triazoles 20a and 20b. Nevertheless, the 1,2,3-triazole analogue of the most potent tetrazole had a lowered inhibitory activity by a factor of 100 .

The basic imidazole is a highly different five-membered nitrogen-containing heteroaromatic compared with the acidic tetrazole. To our surprise, compound $27 \mathrm{a}$, which is the 2imidazole analogue of $\mathbf{1 a}$, was more potent than the parent compound. Furthermore, modifications of the linker length, resulting in compounds $\mathbf{2 6 a}$ and $\mathbf{2 8 a}$, did not have a significant effect on the inhibitory activity. The 4-imidazole analogue 29a was slightly less potent than 1a and the 3-pyrazolyl analogue 30a had an $\mathrm{IC}_{50}$ value in the micromolar range. The purity of compound 29a was only $86 \%$, and the $\mathrm{IC}_{50}$ value should be viewed with this in mind. Interestingly, compound $27 \mathbf{b}$, the 2 imidazole analogue of $\mathbf{1 b}$, was less potent than the parent compound, indicating that the 2-imidazole ring in combination with a central alanyl residue does not result in the same favorable binding mode as with a central prolyl residue. 

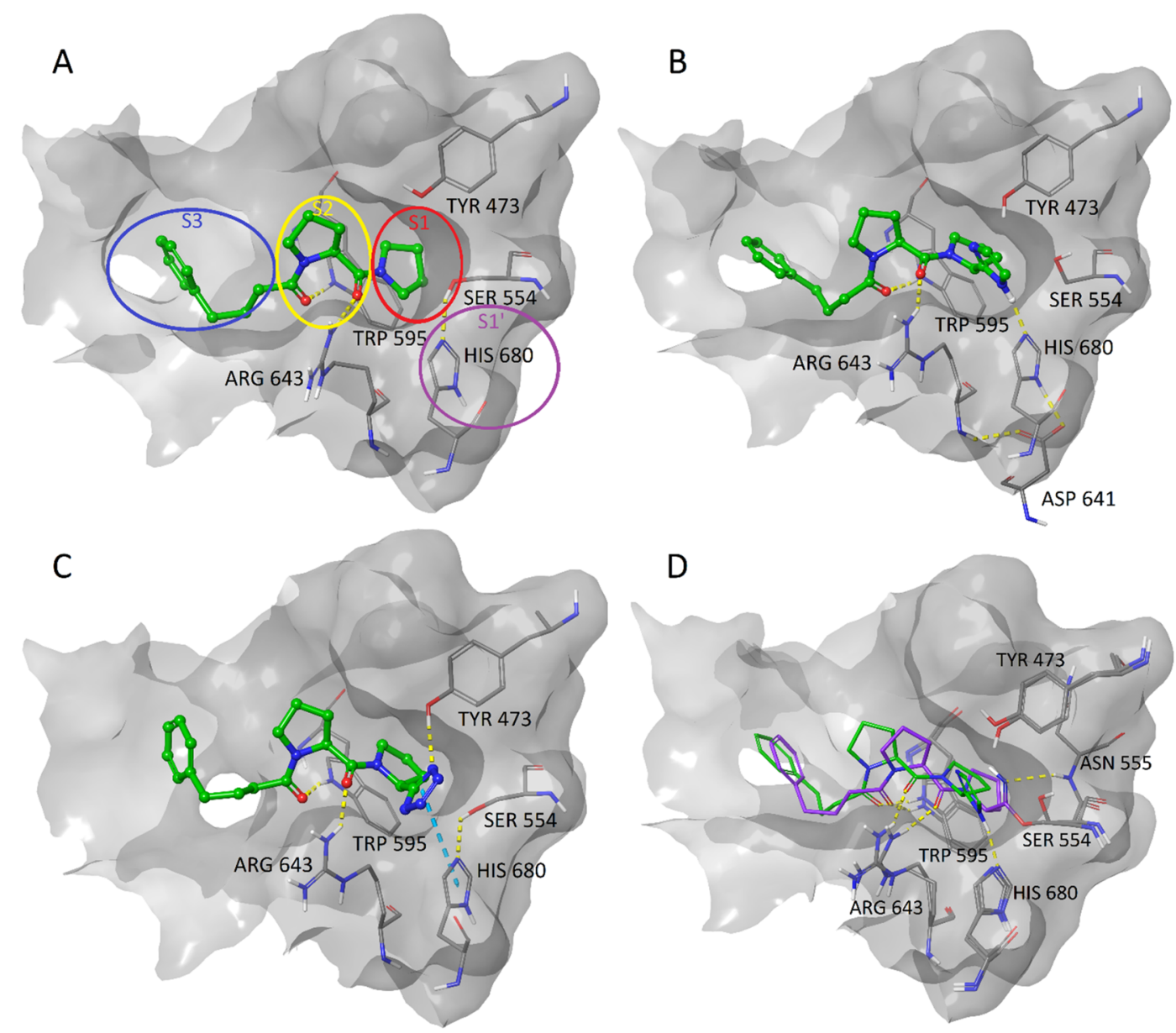

Figure 1. Induced fit docking poses at the proteolytic active site of PREP (PDB: 3DDU) for (A) SUAM-1221 with approximate amino acid binding sites S3-S1' circled; (B) 27a; (C) 1a; (D) 27a (green) superimposed with a crystal structure of PREP with covalently bound KYP-2047 (purple)(PDB: 4AN0). Hydrogen bonds are shown as yellow dashed lines and $\pi-\pi$ stacking interactions as blue dashed lines.

Docking studies were performed to gain more insight on the binding modes of the compounds containing different heteroaryls. The compounds in Table 1 were docked into the proteolytic active site of PREP. ${ }^{27}$ SUAM-1221, ${ }^{28}$ a noncovalently binding peptidic PREP inhibitor, and the cocrystallized ligand (GSK552) were docked as references. Docking was initially performed using Glide, ${ }^{29}$ a rigid docking method, and repeated using an induced fit docking protocol, ${ }^{30}$ which allows for movement in the side chains. Most of the docked compounds had a pose where the two carbonyls interact with Trp595 and Arg643 and pyrrolidine is placed in the $S 1$ pocket (Figure 1A), as is common with most peptidic PREP inhibitors. ${ }^{31}$ Interestingly, the imidazole group in compound 27a was able to act as a hydrogen bond donor to the catalytic His680 residue (Figure 1B). As in the catalytic triad, His680 further donates a hydrogen bond to Asp641. The corresponding alanine analogue, compound $27 \mathbf{b}$, did not form this interaction. Several of the compounds containing other heteroaryls could orientate similarly in the pocket, but they could not form the hydrogen bond to His680 without losing an interaction with Trp595 or Arg643. Instead, they formed hydrogen bonds to Tyr473, which is located on the opposite side of the groove (Figure $1 \mathrm{C}$ and Supporting Information Figures S2 and S4). Compound 27a was also able to interact with Tyr473 instead of His680 in some poses (Supporting Information Figure S3A). The predicted binding mode of $\mathbf{2 7 a}$ was compared to a crystal structure where KYP-2047 is covalently bound to $\mathrm{PREP}^{32}$ by superimposing the protein structures (Figure 1D). This showed that the five-membered heteroaryl may prevent the pyrrolidine of 27 a from fully occupying the S1 pocket, which also shifts the interaction to Arg643 compared with that of the covalently bound ligand. However, the interaction to Trp595 as well as the position of the hydrophobic chain at S3 are very similar for the two compounds.

Reference compound 2a contains an electrophilic carbonyl group connecting the pyrrolidine and imidazole rings. The additional carbonyl group prevents the imidazole ring from orientating similarly to that of $27 \mathrm{a}$, while still maintaining its interactions to Trp595 and Arg643. However, Tsutsumi et al. hypothesized that 2 a binds covalently to Ser554 at the carbonyl, which could result in the heteroaryl positioning suitably to accept a hydrogen bond from His680. ${ }^{18}$ They based this theory on a previously crystallized structure, showing the interaction between a similar peptide-like compound and porcine pancreatic elastase, which is also a serine protease with a catalytic triad consisting of Ser, His, and Asp. ${ }^{33}$ PREP was later crystallized with covalently bound Z-prolyl-prolinal (ZPP), where a similarly positioned aldehyde and Ser554 form a hemiacetal adduct. ${ }^{31} \mathrm{ZPP}$ was as potent of an inhibitor as $\mathbf{2 a}$ when assayed by Tsutsumi et al., ${ }^{18}$ suggesting the high inhibitory activities of these compounds are probably based on 
the ability to form the covalent bond. Compound 27a and its close analogues cannot form this covalent bond and are therefore the only compounds predicted to bind to His680 in the presented manner.

The effect of the compounds on autophagy was determined by using GFP-LC3B-RFP expressing HEK-293 cells. ${ }^{15,34}$ The effect on $\alpha$ Syn dimerization was evaluated with a protein fragment complementation assay (PCA) by using N2A cells. ${ }^{10,15,16}$ The increase in autophagic flux was measured as a decrease in GFP signal due to increased degradation of GFPLC3B, and the decrease in $\alpha$ Syn dimerization was measured as a decrease in luminescence, both compared with DMSO (Table 1). KYP-2047 was used as a reference for $\alpha$ Syn dimerization as it is known to significantly decrease this activity, lowering the luminescence to $75 \%$ of the DMSO control. $^{15}$ Rapamycin and starvation are known to induce autophagy, lowering the fluorescence to $65-70 \%$ in our assays, and were therefore used as reference compounds for this. Test compounds were assayed at $10 \mu \mathrm{M}$ concentration with $0.1 \%$ DMSO. A graphical representation of the mean values $( \pm$ SEM) can be seen in the Supporting Information (Figure S1).

The tetrazoles were previously shown to decrease PREP catalyzed $\alpha$ Syn dimerization. ${ }^{16}$ The effect of these tetrazoles on autophagy was determined for the first time in this study. Compound $\mathbf{1 b}$ was effective at inducing autophagy and compound 1c had some effect, while compounds 1a, 1d, and 1e had no significant activity. Varying the linker length in 1a and $1 b$, resulting in compounds $15 a, 15 b, 16 a$, and $16 b$, reduced the modulating activity for both $\alpha$ Syn dimerization and autophagy. Interestingly, substituting the phenyl group of 1a with a 2-thienyl group, resulting in compound 17a, maintained some activity on $\alpha$ Syn dimerization and slightly improved the activity in inducing autophagy. The alaninebased 2-thienyl analogue $17 \mathrm{~b}$ was inactive for both functions. Methylating the tetrazole in $\mathbf{1 a}$ led to the two regioisomers 18a and 19a, which were capable of inducing autophagy but lost the activity on $\alpha$ Syn dimerization.

Compound 27a, the 2-imidazole analogue of 1a, was able to decrease $\alpha$ Syn dimerization more than the parent compound, reaching the same level of activity as reference compound KYP-2047. However, it had no effect on autophagy. Modifying the linker length, resulting in compounds 26a and 28a, led to a significant decrease in the effect on $\alpha$ Syn dimerization, with the shorter chain analogue 26 a still retaining some modulating activity. Compound $\mathbf{2 7} \mathbf{b}$, the 2 -imidazole analogue of $\mathbf{1 b}$, did not retain either of the activities of the parent compound. Compounds 20a, 29a, and 30a, the 1,2,4-triazolyl, 4-imidazole, and 3-pyrazolyl analogues of 1a, respectively, showed some minor activity in modulating autophagy but no activity on $\alpha$ Syn dimerization. The lack of activity on $\alpha$ Syn dimerization and autophagy by reference compound 2a was also observed.

The new results support the earlier observations for small molecular ligands, that inhibition of the proteolytic activity of PREP does not correlate with the ability to modulate other PPI mediated functions of PREP. ${ }^{15}$ The disconnected SARs are obvious for the 2-imidazoles 26a, 27a, and 28a, where changing the linker length has a minor effect on the inhibitory activity but significantly affects the effect on $\alpha$ Syn dimerization. Ligand binding outside the area occupied by Suc-Gly-ProAMC, the substrate used in the assay for proteolytic activity, would be the most logical explanation for the disconnected SARs. It should be emphasized that modulations of PPIs are observed with a ligand concentration far below the $\mathrm{IC}_{50}$ value for some compounds, such as $18 \mathbf{a}, \mathbf{2 0 a}$, and 30a, and that some highly potent inhibitors do not modulate the PPIs, such as 2 a and 28a.

In conclusion, the 2-imidazoles demonstrate a surprisingly high inhibitory activity compared with the other heteroaromatics in the novel compound series. Binding to the active site was explored using molecular docking as the novel imidazoles lack a covalently binding electrophile and cannot bind with the same binding mode as reference compound $\mathbf{2 a}$. A possible interaction between the imidazole ring and the catalytic His680 residue was discovered, which could explain the high inhibitory activity of the 2 -imidazole analogues. The imidazoles are slightly less polar, and as basic compounds they ionize in the opposite direction compared with the tetrazoles, which gives them a good starting point in drug development. The disconnected SARs between inhibition of proteolytic activity and modulation of PPIs was observed throughout the compound series, and this study identified the linker length on the opposite side of the molecule from the heteroaryl to be a highly critical structural feature for modulating PPI derived functions of PREP. This supports the hypothesis of a second binding site not interfering with the active site, where ligand binding can restrict the conformational freedom of PREP differently from ligand binding to the active site.

\section{ASSOCIATED CONTENT}

\section{(s) Supporting Information}

The Supporting Information is available free of charge at https://pubs.acs.org/doi/10.1021/acsmedchemlett.1c00399.

Synthesis of compounds 2-30, biological experimental data, molecular docking experimental data, additional figures illustrating induced fit docking poses, and UPLC traces for the tested compounds (PDF)

\section{AUTHOR INFORMATION}

\section{Corresponding Author}

Henri T. Pätsi - Drug Research Program, Division of Pharmaceutical Chemistry and Technology, Faculty of Pharmacy, University of Helsinki, 00014 Helsinki, Finland; 이이.org/0000-0003-0802-2557; Email: henri.t.patsi@ helsinki.fi

\section{Authors}

Tommi P. Kilpeläinen - Drug Research Program, Division of Pharmacology and Pharmacotherapy, Faculty of Pharmacy, University of Helsinki, 00014 Helsinki, Finland; (1) orcid.org/0000-0003-1007-3273

Samuli Auno - Drug Research Program, Division of Pharmacology and Pharmacotherapy, Faculty of Pharmacy, University of Helsinki, 00014 Helsinki, Finland; (1) orcid.org/0000-0003-2931-6853

Pyry M. J. Dillemuth - Drug Research Program, Division of Pharmaceutical Chemistry and Technology, Faculty of Pharmacy, University of Helsinki, 00014 Helsinki, Finland; (1) orcid.org/0000-0002-4210-6781

Khaled Arja - Drug Research Program, Division of Pharmaceutical Chemistry and Technology, Faculty of Pharmacy, University of Helsinki, 00014 Helsinki, Finland

Maija K. Lahtela-Kakkonen - School of Pharmacy, Faculty of Health Sciences, University of Eastern Finland, 70211 Kuopio, Finland; 이이.org/0000-0001-7163-7728 
Timo T. Myöhänen - Drug Research Program, Division of Pharmacology and Pharmacotherapy, Faculty of Pharmacy, University of Helsinki, 00014 Helsinki, Finland; School of Pharmacy, Faculty of Health Sciences, University of Eastern Finland, 70211 Kuopio, Finland; Integrative Physiology and Pharmacology Unit, Institute of Biomedicine, University of Turku, 20014 Turku, Finland

Erik A. A. Wallén - Drug Research Program, Division of Pharmaceutical Chemistry and Technology, Faculty of Pharmacy, University of Helsinki, 00014 Helsinki, Finland; (1) orcid.org/0000-0002-2269-5179

Complete contact information is available at:

https://pubs.acs.org/10.1021/acsmedchemlett.1c00399

\section{Author Contributions}

Chemistry was contributed by H.T.P, P.M.J.D, K.A., and E.A.A.W.; pharmacology by T.P.K., S.A., and T.T.M.; and molecular docking studies by H.T.P. and M.K.L.K. All authors have given approval to the final version of the manuscript.

\section{Notes}

The authors declare no competing financial interest.

\section{ACKNOWLEDGMENTS}

The authors wish to acknowledge Nina Sipari from Viikki Metabolomics Unit for mass spectrometry and CSC - IT Center for Science, Finland, for computational resources. The study was supported by grants from Academy of Finland (318327), Sigrid Jusélius Foundation, HiLIFE, and Business Finland for T.T.M. and E.A.A.W.

\section{ABBREVIATIONS}

$\begin{array}{ll}\text { AMC } & \text { 7-amino-4-methyl coumarin } \\ \alpha \text { Syn } & \text { alpha-synuclein } \\ \text { br } & \text { broad } \\ \text { DMEM } & \text { Dulbecco's Modified Eagle Medium } \\ \text { DMF-DMA } & N, N \text {-dimethylformamide dimethyl acetal } \\ \text { HDMS } & \text { hexamethyldisilazane } \\ \text { p-ABSA } & \text { 4-acetamidobenzenesulfonyl azide } \\ \text { PP2A } & \text { protein phosphatase 2A } \\ \text { PPI } & \text { protein-protein interaction } \\ \text { PREP } & \text { prolyl oligopeptidase } \\ \text { TEMPO } & \text { 2,2,6,6-tetramethylpiperidine 1-oxyl } \\ \text { TosMIC } & \text { p-toluenesulfonylmethyl isocyanide }\end{array}$

\section{REFERENCES}

(1) Koida, M.; Walter, R. Post-proline cleaving enzyme. Purification of this endopeptidase by affinity chromatography. J. Biol. Chem. 1976, 251 (23), 7593-7599.

(2) Walter, R.; Shlank, H.; Glass, J. D.; Schwartz, I. L.; Kerenyi, T. D. Leucylglycinamide released from oxytocin by human uterine enzyme. Science 1971, 173 (3999), 827-829.

(3) García-Horsman, J. A.; Männistö, P. T.; Venäläinen, J. I. On the role of prolyl oligopeptidase in health and disease. Neuropeptides 2007, 41 (1), 1-24.

(4) Dresdner, K.; Barker, L. A.; Orlowski, M.; Wilk, S. Subcellular distribution of prolyl endopeptidase and cation-sensitive neutral endopeptidase in rabbit brain. J. Neurochem. 1982, 38 (4), 11511154.

(5) Männisto, P. T.; Venäläinen, J.; Jalkanen, A.; García-Horsman, J. A. Prolyl oligopeptidase: a potential target for the treatment of cognitive disorders. Drug News Perspect. 2007, 20 (5), 293-305.

(6) Jalkanen, A. J.; Savolainen, K.; Forsberg, M. M. Inhibition of prolyl oligopeptidase by KYP-2047 fails to increase the extracellular neurotensin and substance $\mathrm{P}$ levels in rat striatum. Neurosci. Lett. 2011, 502 (2), 107-111.

(7) Biber, N.; Brockschneider, D.; Gericke, K. M.; Kölling, F.; Lustig, K.; Meding, J.; Meier, H.; Neubauer, T.; Schäfer, M.; Timmermann, A.; Zubov, D.; Terjung, C.; Lindner, N.; Badock, V.; Moosmayer, D.; Ondozabal, H. M.; Moore, S.; Schulz, A. Substituted 5,6,7,8tetrahydro[1,2,4] triazolo[4,3-a]pyridine-3(2h)-ones and 2,5,6,7-tetrahydro-3h-pyrrolo[2,1-c] $[1,2,4]$ triazol-3-ones, and use thereof. WO2017194459A1, 2017.

(8) Biber, N.; Brockschnieder, D.; Kölling, F.; Meding, J.; Ondozabal, H. M.; Neubauer, T.; Schäfer, M.; Zubov, D.; Terjung, C. Substituted 2,4-dihydro-3h-1,2,4-triazol-3-ones and use of same. WO2019091847A1, 2019.

(9) Development pipeline. https://pharma.bayer.com/developmentpipeline (accessed July 12, 2021).

(10) Savolainen, M. H.; Yan, X.; Myöhänen, T. T.; Huttunen, H. J. Prolyl oligopeptidase enhances $\alpha$-synuclein dimerization via direct protein-protein interaction. J. Biol. Chem. 2015, 290 (8), 5117-5126.

(11) Savolainen, M. H.; Richie, C. T.; Harvey, B. K.; Männistö, P. T.; Maguire-Zeiss, K. A.; Myöhänen, T. T. The beneficial effect of a prolyl oligopeptidase inhibitor, KYP-2047, on alpha-synuclein clearance and autophagy in A30P transgenic mouse. Neurobiol. Dis. 2014, 68, 1-15.

(12) Svarcbahs, R.; Jäntti, M.; Kilpeläinen, T.; Julku, U. H.; Urvas, L.; Kivioja, S.; Norrbacka, S.; Myöhänen, T. T. Prolyl oligopeptidase inhibition activates autophagy via protein phosphatase 2A. Pharmacol. Res. 2020, 151, 104558.

(13) Myöhänen, T. T.; Hannula, M. J.; Van Elzen, R.; Gerard, M.; Van Der Veken, P.; García-Horsman, J. A.; Baekelandt, V.; Männistö, P. T.; Lambeir, A. M. A prolyl oligopeptidase inhibitor, KYP-2047, reduces $\alpha$-synuclein protein levels and aggregates in cellular and animal models of Parkinson's disease. Br. J. Pharmacol. 2012, 166 (3), $1097-1113$.

(14) Svarcbahs, R.; Julku, U. H.; Myöhänen, T. T. Inhibition of Prolyl Oligopeptidase Restores Spontaneous Motor Behavior in the $\alpha$ Synuclein Virus Vector-Based Parkinson's Disease Mouse Model by Decreasing $\alpha$-Synuclein Oligomeric Species in Mouse Brain. J. Neurosci. 2016, 36 (49), 12485-12497.

(15) Kilpeläinen, T. P.; Hellinen, L.; Vrijdag, J.; Yan, X.; Svarcbahs, R.; Vellonen, K.-S.; Lambeir, A.-M.; Huttunen, H.; Urtti, A.; Wallen, E. A. A.; Myöhänen, T. T. The effect of prolyl oligopeptidase inhibitors on alpha-synuclein aggregation and autophagy cannot be predicted by their inhibitory efficacy. Biomed. Pharmacother. 2020, $128,110253$.

(16) Kilpelainen, T. P.; Tyni, J. K.; Lahtela-Kakkonen, M. K.; Etelainen, T. S.; Myohanen, T. T.; Wallen, E. A. A. Tetrazole as a Replacement of the Electrophilic Group in Characteristic Prolyl Oligopeptidase Inhibitors. ACS Med. Chem. Lett. 2019, 10 (12), $1635-1640$

(17) Tsirigotaki, A.; Elzen, R. V.; Veken, P. V.; Lambeir, A. M.; Economou, A. Dynamics and ligand-induced conformational changes in human prolyl oligopeptidase analyzed by hydrogen/deuterium exchange mass spectrometry. Sci. Rep. 2017, 7 (1), 2456.

(18) Tsutsumi, S.; Okonogi, T.; Shibahara, S.; Ohuchi, S.; Hatsushiba, E.; Patchett, A. A.; Christensen, B. G. Synthesis and structure-activity relationships of peptidyl alpha-keto heterocycles as novel inhibitors of prolyl endopeptidase. J. Med. Chem. 1994, 37 (21), 3492-3502.

(19) Lloyd, J.; Finlay, H. J.; Vacarro, W.; Hyunh, T.; Kover, A.; Bhandaru, R.; Yan, L.; Atwal, K.; Conder, M. L.; Jenkins-West, T.; Shi, H.; Huang, C.; Li, D.; Sun, H.; Levesque, P. Pyrrolidine amides of pyrazolodihydropyrimidines as potent and selective KV1.5 blockers. Bioorg. Med. Chem. Lett. 2010, 20 (4), 1436-1439.

(20) Tran, T. D.; Wakenhut, F.; Pickford, C.; Shaw, S.; Westby, M.; Smith-Burchnell, C.; Watson, L.; Paradowski, M.; Milbank, J.; Brimage, R. A.; Halstead, R.; Glen, R.; Wilson, C. P.; Adam, F.; Hay, D.; Chiva, J. Y.; Nichols, C.; Blakemore, D. C.; Gardner, I.; Dayal, S.; Pike, A.; Webster, R.; Pryde, D. C. The discovery of potent 
nonstructural protein 5A (NS5A) inhibitors with a unique resistance profile-Part 1. ChemMedChem 2014, 9 (7), 1378-1386.

(21) Zhang, B.; Jiang, Z.; Zhou, X.; Lu, S.; Li, J.; Liu, Y.; Li, C. The synthesis of chiral isotetronic acids with amphiphilic imidazole/ pyrrolidine catalysts assembled in oil-in-water emulsion droplets. Angew. Chem., Int. Ed. 2012, 51 (52), 13159-13162.

(22) Kitbunnadaj, R.; Hoffmann, M.; Fratantoni, S. A.; Bongers, G.; Bakker, R. A.; Wieland, K.; el Jilali, A.; De Esch, I. J.; Menge, W. M.; Timmerman, H.; Leurs, R. New high affinity $\mathrm{H} 3$ receptor agonists without a basic side chain. Bioorg. Med. Chem. 2005, 13 (23), 63096323.

(23) Jepsen, T. H.; Kristensen, J. L. In situ generation of the OhiraBestmann reagent from stable sulfonyl azide: scalable synthesis of alkynes from aldehydes. J. Org. Chem. 2014, 79 (19), 9423-9426.

(24) Jin, T.; Kamijo, S.; Yamamoto, Y. Copper-Catalyzed Synthesis of N-Unsubstituted 1,2,3-Triazoles from Nonactivated Terminal Alkynes. Eur. J. Org. Chem. 2004, 2004 (18), 3789-3791.

(25) Venäläinen, J. I.; Juvonen, R. O.; Forsberg, M. M.; GarciaHorsman, A.; Poso, A.; Wallen, E. A.; Gynther, J.; Männistö, P. T. Substrate-dependent, non-hyperbolic kinetics of pig brain prolyl oligopeptidase and its tight binding inhibition by JTP-4819. Biochem. Pharmacol. 2002, 64 (3), 463-471.

(26) Jarho, E. M.; Venäläinen, J. I.; Huuskonen, J.; Christiaans, J. A. M.; Garcia-Horsman, J. A.; Forsberg, M. M.; Järvinen, T.; Gynther, J.; Männistö, P. T.; Wallén, E. A. A. A Cyclopent-2-enecarbonyl Group Mimics Proline at the P2 Position of Prolyl Oligopeptidase Inhibitors. J. Med. Chem. 2004, 47 (23), 5605-5607.

(27) Haffner, C. D.; Diaz, C. J.; Miller, A. B.; Reid, R. A.; Madauss, K. P.; Hassell, A.; Hanlon, M. H.; Porter, D. J.; Becherer, J. D.; Carter, L. H. Pyrrolidinyl pyridone and pyrazinone analogues as potent inhibitors of prolyl oligopeptidase (POP). Bioorg. Med. Chem. Lett. 2008, 18 (15), 4360-4363.

(28) Arai, H.; Nishioka, H.; Niwa, S.; Yamanaka, T.; Tanaka, Y.; Yoshinaga, K.; Kobayashi, N.; Miura, N.; Ikeda, Y. Synthesis of prolyl endopeptidase inhibitors and evaluation of their structure-activity relationships: in vitro inhibition of prolyl endopeptidase from canine brain. Chem. Pharm. Bull. 1993, 41 (9), 1583-1588.

(29) Glide, Schrödinger Release 2020-4; Schrödinger, 2020.

(30) Induced Fit Docking protocol, Schrödinger Release 2020-4; Schrödinger, 2020.

(31) Fülöp, V.; Böcskei, Z.; Polgár, L. Prolyl oligopeptidase: an unusual beta-propeller domain regulates proteolysis. Cell 1998, 94 (2), 161-170.

(32) Kaszuba, K.; Róg, T.; Danne, R.; Canning, P.; Fülöp, V.; Juhász, T.; Szeltner, Z.; St. Pierre, J. F.; García-Horsman, A.; Männistö, P. T.; Karttunen, M.; Hokkanen, J.; Bunker, A. Molecular dynamics, crystallography and mutagenesis studies on the substrate gating mechanism of prolyl oligopeptidase. Biochimie 2012, 94 (6), 13981411.

(33) Edwards, P. D.; Meyer, E. F.; Vijayalakshmi, J.; Tuthill, P. A.; Andisik, D. A.; Gomes, B.; Strimpler, A. Design, synthesis, and kinetic evaluation of a unique class of elastase inhibitors, the peptidyl.alpha.ketobenzoxazoles, and the $\mathrm{x}$-ray crystal structure of the covalent complex between porcine pancreatic elastase and Ac-Ala-Pro-Val-2benzoxazole. J. Am. Chem. Soc. 1992, 114 (5), 1854-1863.

(34) Kaizuka, T.; Morishita, H.; Hama, Y.; Tsukamoto, S.; Matsui, T.; Toyota, Y.; Kodama, A.; Ishihara, T.; Mizushima, T.; Mizushima, N. An Autophagic Flux Probe that Releases an Internal Control. Mol. Cell 2016, 64 (4), 835-849. 